\title{
Perencanaan Eskalator Lantai Satu ke Dua pada Gedung Direktorat Politeknik Negeri Samarinda dengan Kendali PLC
}

\author{
Muhammad Hendrik Septiawan ${ }^{1}$, Dadang Suherman ${ }^{2 *}$, Prihadi Murdiyat ${ }^{3}$ \\ 1,2,3 Jurusan Teknik Elektro, Politeknik Negeri Samarinda, Samarinda 75131, Indonesia \\ *dadang.shm@gmail.com
}

\begin{abstract}
Escalators help people to get up and down the floor more easily, safely and quickly, so it is more efficient in the use of time and energy. The need for an escalator is also seen in the Samarinda State Polytechnic Directorate Building, which is a 4-storey building with stairs in the middle of the building. Some people may be tired to go up to the second, third and fourth floors. Seeing the need for an escalator to be installed instead of a staircase, this study designed an escalator with a PLC (Programmable Logic Controller) control system that combines several types of sensors including: infrared sensors and security sensors such as handrail entry switches, skirt guard safety switches, driving chains safety switch, step chain safety switch, and step safety switch. The desain includes calculating the length of the escalator to be installed, the motor power capacity to be used and the escalator control system. This system can control the safety and efficiency of electricity usage on the escalator. Escalators will work if a passenger is detected by an infrared sensor. If no passengers are detected, the escalator will stop working within the specified time period. When there is a problem in the system that can result in an accident to the passenger, the security sensor will work to stop the escalator.
\end{abstract}

Keywords: escalator, PLC, infrared sensor, security sensor

\begin{abstract}
Abstrak: Eskalator atau tangga berjalan akan membantu manusia untuk naik turun lantai dengan lebih mudah, aman dan cepat, sehingga lebih efisien dalam penggunaan waktu dan tenaga. Kebutuhan akan escalator juga tampak pada Gedung Direktorat Politeknik Negeri Samarinda, yang merupakan bangunan bertingkat 4 dengan tangga berada di tengah gedung. Sebagian orang akan lelah untuk naik ke lantai dua, tiga, dan empat. Melihat perlunya escalator untuk dipasang menggantikan tangga biasa, maka pada penelitian ini direncanakan eskalator dengan sistem kendali PLC (Programmable Logic Controller) yang menggabungkan beberapa jenis sensor antara lain: sensor infrared dan sensor keamanan seperti, handrail entry switch, skirt guard safety switch, driving chain safety switch, step chain safety switch, dan step safety switch. Perencanaan yang dilakukan meliputi perhitungan panjang eskalator yang akan dipasang, kapasitas daya motor yang akan digunakan dan sistem kontrol eskalator tersebut. Sistem ini dapat melakukan kontrol keamanan dan efisiensi penggunaan listrik pada eskalator. Eskalator akan bekerja apabila ada penumpang yang dideteksi oleh sensor infrared. Jika tidak ada penumpang yang dideteksi maka eskalator akan berhenti bekerja dalam jangka waktu yang telah ditentukan. Ketika terjadi masalah pada sistem yang dapat mengakibatkan kecelakaan terhadap penumpang maka sensor keamanan akan bekerja untuk menghentikan eskalator.
\end{abstract}

Kata kunci : eskalator, PLC, sensor infrared, sensor keamanan

\section{PENDAHULUAN}

Gedung Direktorat Politeknik Negeri Samarinda merupakan bangunan empat lantai dengan anak tangga yang berada di bagian tengahnya. Selain lantai dasar yang terisi kantor, kantor-kantor lain juga berada di lantai satu dan lantai dua di mana kantor Direktur berada. Di lantai tiga terdapat ruang besar untuk rapat atau seminar dan sedikit ruang kantor. Mengingat seringnya orang lalu Lalang hamper ke semua lantai, naik turun tangga akan membuat orang lelah. Karena itu, penggunaan eskalator pada Gedung Direktorat Politeknik Negeri Samarinda akan membantu manusia untuk naik turun lantai dengan lebih mudah dan cepat. Sistem kontrol eskalator yang menggunakan PLC (Programmable Logic Controller) dibutuhkan untuk mengoperasikan eskalator secara otomatis tanpa dioperasikan oleh operator. Berdasarkan uraian tersebut maka dibuatlah penelitian yang berupa perencanaan 
eskalator yang menghubungkan antara lantai satu ke lantai dua dengan kendali PLC. Perencanaan dilakukan baik pada bagian mekanik maupun elektrik. .

\section{A. Pengertian dan Prinsip Kerja Eskalator}

Eskalator atau tangga berjalan adalah salah satu transportasi vertikal berupa conveyor untuk mengangkut orang yang terdiri dari tangga terpisah yang dapat bergerak keatas dan kebawah mengikuti jalur yang berupa rel atau rantai yang digerakkan oleh motor [1]. Cara kerja eskalator sebenarnya sederhana, Tangga eskalator ini dilengkapi dengan 2 buah roda yang melekat sepanjang rel. Suatu roda (wheel) bagian atas tangga melekat pada rel luar (outer rail) yang berfungsi memandu tangga pada posisinya. roda yang kedua (return wheel) melekat diatas rel dalam (timer rail) yang berfungsi untuk tempat berjalannya tangga. Pegangan (handrail) merupakan tempat di mana pengguna memastikan dirinya aman. Pegangan ini bergerak sesuai pergerakan tangga. Rantai pemandu (chain guide) melekat pada roda penggerak (drive gear) yang digerakkan oleh motor listrik yang berfungsi untuk menggerakkan tangga eskalator. Saat motor listrik berputar, puli (sistem yang menghubungkan semua bagian) akan memutar roda penggerak. Tangga akan digerakkan sepanjang relnya dengan bantuan tali pemandu. Pergerakan tangga akan sama dengan pergerakan pegangan tangan karena roda penggerak juga dihubungkan dengan handrail drive

\section{B. Komponen-Komponen Eskalator}

Sebuah eskalator mempunyai lebih dari sepuluh komponen utama seperti truss, motor penggerak, sistem transmisi, tangga, track system, balustrade, decking, peralatan pengaman dan sistem kelistrikan [2]. Truss merupakan baja struktural yang menopang bobot dan beban eskalator dan komponen lain seperti, panel kontrol, drive unit, step dan handrail yang bergerak dan komponen lainnya yang ditempatkan di dalam eskalator [3]. Track berfungsi untuk mengarahkan gerak luncuran roda rantai penggerak anak tangga (step chain roller) dan roda anak tangga (step roller) [3]. Sementara itu rantai (chain) dan gigi (sprocket) merupakan peralatan penggerak anak tangga dan pegangan tangan.

Lebih jauh, Moving handrail merupakan sebuah pegangan yang bergerak di bagian atas balustrade dan disinkronisasikan dengan step yang berfungsi untuk membantu penumpang pada saat melangkah masuk atau keluar dari anak tangga agar penumpang tidak jatuh atau terpeleset [2]. Sedangkan, anak tangga (step) merupakan tempat pijakan dari penumpang eskalator dan bagian permukaannya harus dalam keadaan horizontal saat membawa penumpang.

Lantai pijak berfungsi untuk tempat pijakan masuk dan keluar juga berfungsi sebagai penutup bagian mekanis escalator [2]. Komponen lain adalah balustrade yang merupakan dinding kiri dan kanan dari eskalator. Untuk drive unit, bagaian-bagian penyusunnya adalah : motor penggerak, reduction gearbox, rem magnet, dan poros. Selanjutnya again lain dari drive unit adalah rem magnet digunakan untuk menahan gerakan anak tangga pada saat motor berhenti, ataupun pada saat suplai daya terputus dipasang rem magnet. Bagian terakhir adalah shaft poros.

Salah satu kontak/saklar adalah handrail entry switch yang berfungsi untuk mematikan eskalator jika ada tangan atau objek lain masuk ke dalam handrail escalator [2]. Selain itu ada juga skirt guard safety switch yang berfungsi untuk mematikan eskalator jika terdapat benda yang masuk di antara skirt guard dan step pada eskalator, dipasang pada sisi kanan dan kiri pada escalator. Selanjutnya adalah driving chain safety switch yang berguna untuk menghentik an eskalator jika rantai penggerak putus atau terlalu longgar. Kemudian ada step chain safety switch yang berfungsi untuk menghentikan eskalator jika rantai step mengalami putus atau longgar. Yang terakhir adalah step safety switch yang berfungsi untuk menghentikan eskalator jika ada gerakan anak tangga yang tidak normal.

Pada panel operasi terdapat beberapa tombol, yaitu : tombol nyala (starting switch), tombol berhenti (stop switch), dan tombol mati darurat (emergency switch). Selain itu juga terdapat sensor inframerah tyang akan memberikan sinyal ke rangkaian control untuk menjalankan escalator jika dideteksi adanya penumpang pada tangga. Ini akan menghemat energi listrik. 
82 Muhammad Hendrik Septiawan, Dadang Suherman, Prihadi Murdiyat. Perencanaan Eskalator Lantai Satu ke Dua pada Gedung Direktorat Politeknik Negeri Samarinda dengan Kendali PLC

Perangkat yang berada dalam panel control adalah PLC, rangakain terprogram yang berfungsi untuk mengatur motor, atau kontak lainnya berdasarkan sinyal yang diterima dari saklar atau sensor. yang berfungsi atau yang disebut juga programmable logic controller adalah suatu peralatan elektronik yang merupakan sirkuit yang terintegrasi yang biasanya digunakan dalam suatu industri untuk melakukan fungsi control [4]. Selain itu juga ada kontaktor, yaitu saklar listrik yang bekerja berdasarkan prinsip induksi elektromagnetik dan bekerja secara magnetis dalam memutus dan menghubungkan daya yang mana kontaktor berfungsi sebagai pengendali motor maupun komponen listrik lainnya. Ukuran kontaktor, harus dipilih berdasar PUIL [5]. Perangkat lain adalah Miniatur Circuit Breaker (MCB), yang berfungsi sebagai pengaman beban lebih dan arus hubung singkat sehingga mencegah kerusakan pada penghantar dan instalasi. Selain itu juga terdapat pengaman lain bernama Thermal Overload (TOR). Fungsinya adalah memproteksi motor dari kerusakan karena terjadinya beban lebih dengan cara memutuskan suplai ke koil kontaktor (melalui kontak NC nya) [6].

\section{Perancangan Eskalator.}

1. Panjang lintasan untuk sisi miring eskalator

$$
l=\frac{h}{\sin 30^{\circ}}
$$

2. Total jarak tempuh

$$
\mathrm{T}=\left[8+\frac{0,8}{2}+\frac{0.8}{2}+\frac{1,94}{2}\right] \times 2
$$

3. Jumlah step yang dibutuhkan

$$
J=\frac{\text { Total } . j a r a k \cdot t e m p u h}{400,8} .
$$

4. Perhitungan massa total sistem

$$
\mathrm{M}_{\text {Tot }}=\mathrm{M}_{\text {Step }}+\mathrm{M}_{\text {Penumpang }}+\mathrm{M}_{\text {Sprocket }}
$$

5. Penentuan kecepatan putaran sprocket

$$
\mathrm{v}=\omega \times \mathrm{r}
$$

6. Pemilihan gearbox

7. Gaya pada eskalator

$$
\mathrm{F}=\mathrm{m} \times \mathrm{g} \times \sin \theta
$$

8. Perhitungan torsi input dan otput

$$
\frac{n_{1}}{n_{2}}=\frac{T_{2}}{T_{1}}
$$

9. Perhitungan daya mekanik eskalator

$$
P=\frac{T x n}{9,55}
$$

10. Perhitungan daya listrik 


$$
P=\frac{T_{1} x n_{1}}{9,55}
$$

\section{METODE PENELITIAN}

Penelitian ini merupakan perancangan eskalator dari lantai satu ke lantai dua pada gedung direktorat Politeknik Negeri Samarinda.

\section{A. Teknik Pengumpulan Data}

Cara yang digunakan dalam pengambilan data pada penelitian ini adalah:

1. Teknik Observasi (Field Research)

Penulis melakukan observasi secara langsung terhadap obyek penelitian untuk memperoleh datadata yang akan diperlukan dalam penulisan.

2. Studi Literatur

Penulis mengumpulkan data-data dengan membaca dan mempelajari berbagai literatur-literatur yang ada sesuai dengan masalah yang diteliti.

\section{B. Metode Analisis Data}

Adapun penelitian yang dilakukan adalah dengan cara pengumpulan data di lapangan berupa pengukuran panjang lintasan dari lantai satu ke lantai dua. Kemudian merancang kebutuhan eskalator berdasarkan data yang ada, selanjutnya menghitung data dengan menggunakan rumus-rumus yang telah ditentukan untuk mendapatkan hasil perhitungan.

\section{Hasil dan Pembahasan}

\section{A. Rancangan Eskalator}

Eskalator yang direncanakan didesain seperti yang ditunjukkan oleh Gambar 2. Eskalator tersebut bekerja seperti eskalator pada umumnya yaitu motor listrik yang digunakan sebagai sumber tenaga penggerak yang kecepatannya akan disesuaikan dengan gearbox yang akan menggerakkan sprocket bawah, kemudian sprocket akan menggerakkan rantai dan step.

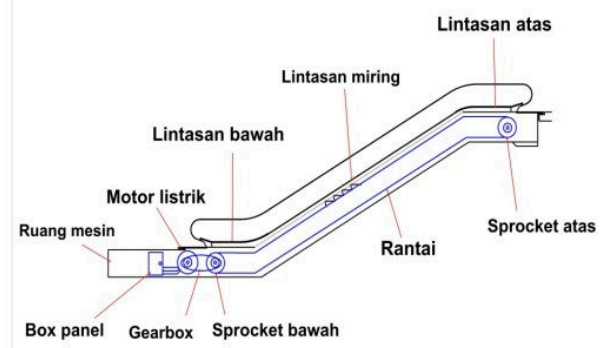

Gambar 2 Peletakan komponen penggerak eskalator

\section{B. Penentuan Panjang Lintasan}

Penentuan panjang lintasan eskalator menyesuaikan panjang dan tinggi tempat penempatan eskalator tersebut. Setelah melakukan pengukuran didapat data sebagai berikut untuk penempatan eskalator:

1. Tinggi lantai satu ke lantai dua $=4$ meter

2. Panjang lantai dua sebagai titik akhir eskalator $=12$ meter

3. Panjang lintasan atas $=800$ mili meter 
84 Muhammad Hendrik Septiawan, Dadang Suherman, Prihadi Murdiyat. Perencanaan Eskalator Lantai Satu ke Dua pada Gedung Direktorat Politeknik Negeri Samarinda dengan Kendali PLC

4. Panjang lintasan bawah $=800$ mili meter

5. Sudut eskalator $=30$

Dengan hasil data tersebut di mana pemilihan eskalator degan sudut $30^{\circ}$ memiliki jumlah step yang lebih banyak dibandingkan pilihan eskalator dengan sudut $35^{\circ}$ selain itu luas area yang digunakan masih mencukupi untuk penggunaan eskalator dengan sudut $30^{\circ}$. Dari data tersebut terlihat bahwa jarak kerja dan lintasan miring untuk eskalator belum diketahui oleh karena itu kita harus mencarinya terlebih dahulu dengan persamaan Phytagoras untuk gambit segitiga siku-siku pada Gambar 3.

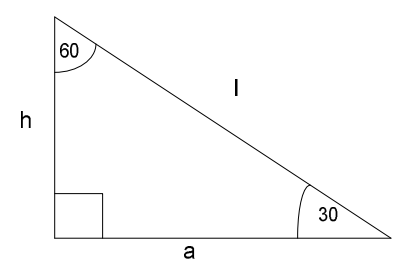

Gambar 3 Segitiga siku-siku perhitungan eskalataor

Panjang lintasan untuk sisi miring eskalator adalah:

$$
1=\frac{h}{\sin 30^{\circ}}=\frac{4}{0,5}=8 \text { meter }
$$

Panjang area kerja untuk eskalator adalah:

$$
\mathrm{a}=\sqrt{\mathrm{l}^{2}-\mathrm{h}^{2}}=\sqrt{8^{2}-4^{2}}=6,928 \text { meter }
$$

Dari perhitungan area kerja eskalator, tinggi dan panjang lintasan miring eskalator maka dapat dibuat sebuah sketsa eskalator yang direncanakan akan dipasang. Penambahan panjang yang digunakan untuk menyediakan ruang mesin seperti terlihat pada Gambar 4.

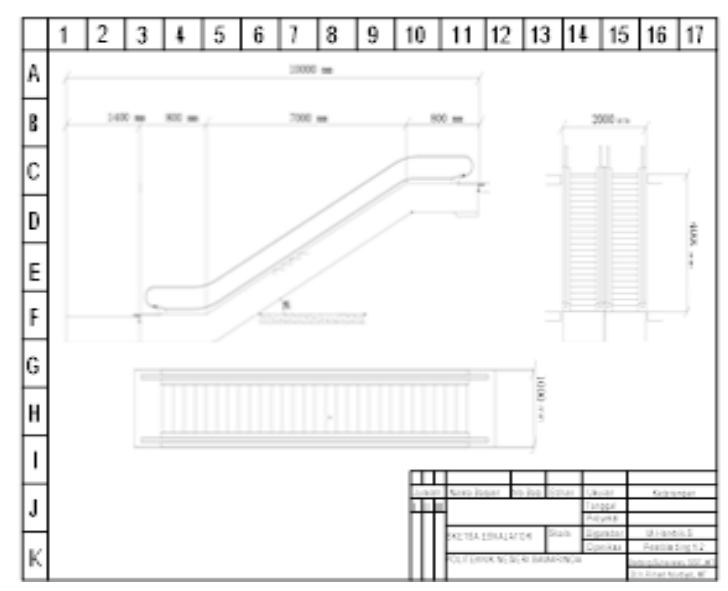

Gambar 4 Sketsa eskalator

\section{Penentuan Total Jarak Yang Ditempuh}

Penentuan total jarak yang ditempuh digunakan untuk mengkalkulasi panjang rantai yang digunakan dan jumlah step yang dibutuhkan. Dengan mendapatkan panjang lintasan bagian bawah = 0,8 meter, panjang lintasan bagian atas $=0,8$ meter. diameter sprocket $=0,617$ meter, keliling sprocket $=1,94$ meter, dan panjang lintasan $=8$ meter, maka:

Total jarak yang ditempuh $=\left[8+\frac{0,8}{2}+\frac{0.8}{2}+\frac{1,94}{2}\right] \times 2=19,54$ meter 


\section{Penentuan Jumlah Step Yang Dibutuhkan}

Pada Gambar 5 tampak bahwa setiap satu step ditopang oleh satu step wheel dengan lebar 400,8 mili meter dan total jarak yang ditempuh step adalah 19,54 meter. Jumlah step yang digunakan total dapat dihitung sebagai berikut:

$$
\text { Jumlah step yang digunakan }=\frac{19,54}{0,4008}=48,75 \text { step }=49 \text { step }
$$

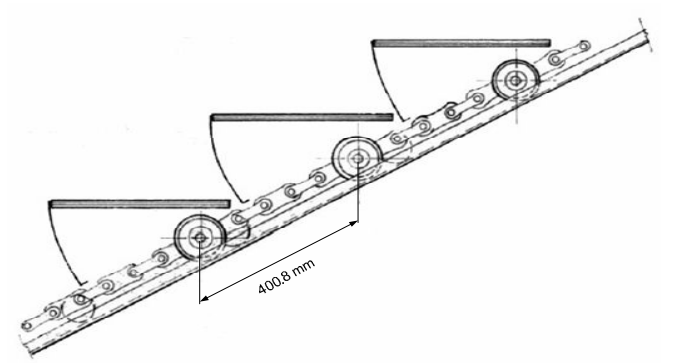

Gambar 5 Jarak antara step wheel

\section{E. Perhitungan Massa Total Sistem}

\section{Massa Step}

Untuk masing-masing step diasumsikan mempunyai massa $=25 \mathrm{Kg}$. Jumlah step yang digunakan berjumlah 49 , maka massa total step dapat dihitung dengan sebagai berikut:

$$
\text { Massa total step }=49 \times 25=1225 \mathrm{~kg}
$$

\section{Massa Penumpang}

Untuk satu kali lintasan, jumlah step adalah total dari jumlah flat step bawah, jumlah flat step atas dan jumlah step lintasan miring. Maka jumlah step penumpang sebagai berikut:

$$
\text { Total step penumpang }=2+2+\frac{8}{0,4008}=24 \text { step }
$$

Massa rata-rata orang dewasa adalah 75 kilogram, sementara di tiap step sepanjang 600 mili meter hanya cukup untuk 1 penumpang. Maka total masa penumpang adalah :

$$
\text { Total massa penumpang }=24 \times 75=1800 \mathrm{~kg}
$$

Untuk pemilihan rantai diambil kekuatan tarik yang besar dan jarak pitch yang tidak terlalu panjang. Untuk jaminan kekuatan sambungan. Dipilih tipe HC120040, maka didapat data-data sebagai berikut: pitch $\mathrm{P}=101,6$ mili meter, berat rata-rata $($ massa $)=5,9$ kilogram $/$ meter, kekuatan tarik rata-rata $=$ 5400 kilogram, diameter roller $=47,6$ mili meter, lebar antara roller link dengan plat $\mathrm{W}=19,1$ mili meter, dan bushing $\mathrm{B}=23,6$ mili meter.

Total jarak yang ditempuh rantai adalah 19,54 m sedangkan massa rantai adalah 5,9 kg/m, maka total massa rantai adalah:

$$
\text { Total massa satu buah rantai }=19,54 \times 5.9=115,29 \mathrm{~kg}
$$

Jika rantai yang akan digunakan adalah 2 buah maka total massa rantai $=115,29 \times 2=230,58 \mathrm{~kg}$ 
86 Muhammad Hendrik Septiawan, Dadang Suherman, Prihadi Murdiyat. Perencanaan Eskalator Lantai Satu ke Dua pada Gedung Direktorat Politeknik Negeri Samarinda dengan Kendali PLC

\section{Massa Sprocket}

Sprocket direncanakan menggunakan bahan dari baja, sehingga dengan nilai berikut : massa jenis bahan $(\partial)=7850 \mathrm{~kg} / \mathrm{m}^{3}$, tebal sprocket $(\mathrm{t})=16 \mathrm{~mm}$, diameter sprocket $(D)=617 \mathrm{~mm}=0,617$ $\mathrm{m}$, dan jumlah gigi $=19$, diperoleh :

$$
\text { Massas sprocket }=\frac{3,14}{4} \times 0,617^{2} \times 0,016 \times 7850=37,53 \mathrm{~kg}
$$

Karena sprocket berjumlah 4 buah maka total massa sprocket adalah $37,53 \times 4=150,12 \mathrm{~kg}$

Dengan menjumlahkan massa-massa yang telah dihitung di atas, di mana : massa step $=1225 \mathrm{~kg}$, massa penumpang $=1800 \mathrm{~kg}$, massa rantai $=230,58 \mathrm{~kg}$, dan massa sprocket $=150,12 \mathrm{~kg}$, maka massa total sistem menjadi $3405,7 \mathrm{~kg}$

\section{F. Penentuan Kecepatan Putaran Sprocket}

Eskalator yang dirancang mengikuti standar eskalator dari Schindler yang memiliki kecepatan sebesar $0,5 \mathrm{~m} / \mathrm{s}$. Selain itu juga kecepatan tersebut mengikuti besar kecepatan yang direkomendasikan oleh buku riksa uji eskalator. Dengan menggunakan data-data berikut : kecepatan eskalator $(\mathrm{v})=0,5$ $\mathrm{m} / \mathrm{s}$, diameter sprocket yang digunakan $=617 \mathrm{~mm}=0,617 \mathrm{~m}$, jari-jari sprocket $=308,5 \mathrm{~mm}=0,3085$ $\mathrm{m}$, dan keliling sprocket $=1,937 \mathrm{~m}$, maka diperoleh kecepatan sudut sprocket :

$$
\begin{aligned}
\mathrm{v} & =\omega \times \mathrm{r} \\
0,5 \mathrm{~m} / \mathrm{s} & =\omega \times 0,3085 \\
\omega & =\frac{0,5}{0,3085}=1,62 \mathrm{rad} / \mathrm{s}
\end{aligned}
$$

Umumnya kecepatan sudut dinyatakan dalam satuan putaran per menit (rpm), sehingga trasformasi kecepatan sudut di atas menjadi :

$$
\begin{aligned}
& \omega=\frac{2 \pi}{60} \mathrm{n} \\
& 1,62=\frac{2 \times 3,14}{60} \mathrm{n} \\
& \mathrm{n}=\frac{1,62 \times 60}{2 \times 3,14}=\frac{97,2}{6,28}=15,5 \mathrm{rpm}
\end{aligned}
$$

Sehingga kecepatan putaran sprocket adalah sebesar 15,5 rpm dengan kecepatan linier eskalator 0,5 $\mathrm{m} / \mathrm{s}$.

\section{G. Pemilihan Gearbox}

Dari kecepatan putaran sprocket yang telah didapat sebesar 15,5 rpm maka kita memilih gearbox dengan menggunakan gear box untuk menurunkan kecepatan maka kita dapat memperoleh torsi yang besar dari daya yang lebih kecil untuk menggerakkan eskalator. Dengan kecepatan putar yang diturunkan maka kecepatan putaran output mendekati 15,5 rpm. Dengan mengacu pada katalog gearbox didapatlah gearbox di mana kecepatan putaran output $\left(n_{2}\right)=14,6$ rpm dan kecepatan putaran input $\left(n_{1}\right)=1400 \mathrm{rpm}$, maka diperoleh gear ratio (i) $=96,2$.

\section{H. Perhitungan Gaya Yang Bekerja Pada Eskalator}

Untuk menghitung besarnya gaya yang bekerja pada escalator digunakan data: massa total $(\mathrm{m})=$ $3405,7 \mathrm{~kg}$, percepatan gravitasi $(\mathrm{g})=9,81 \mathrm{~m} / \mathrm{s}^{2}$, dan sudut eskalator $=30^{\circ}$, maka diperoleh:

$$
\mathrm{F}=\mathrm{m} \times \mathrm{g} \times \sin \theta=3405,7 \times 9,81 \times \sin 30^{\circ}=16704,96 \mathrm{~N}
$$




\section{Perhitungan Torsi Output}

Dengan diperoleh gaya yang bekerja pada eskalator sebesar 16704,96 N, dan jari-jari sprocket (r) sebesar 0,3085 m, diperoleh gaya sebesar 5153,48 Nm.

\section{J. Perhitungan Torsi Input}

Selanjutnya, dengan menggunakan nilai kecepatan putaran input $\left(n_{1}\right)=1400 \mathrm{rpm}$, kecepatan putaran output $\left(n_{2}\right)=14,6 \mathrm{rpm}$, serta torsi output $\left(T_{2}\right)=5153,48 \mathrm{Nm}$, dapat dihitung nilai torsi input sebesar:

$$
\begin{aligned}
\frac{n_{1}}{n_{2}} & =\frac{T_{2}}{T_{1}} \\
\frac{1400}{14,6} & =\frac{5153,48}{T_{1}} \\
T_{1} & =\frac{5153,48 \times 14,6}{1400}=53,74 \mathrm{Nm}
\end{aligned}
$$

\section{K. Perhitungan Daya Mekanik Eskalator}

Dari data torsi output $\left(T_{2}\right)$ sebesar $5153,48 \mathrm{Nm}$ dan kcepatan putaran output $\left(n_{2}\right)=14,6 \mathrm{rpm}$, dapat dihitung daya mekanik escalator sebesar :

$$
\begin{aligned}
& \mathrm{P}=\frac{T \times n}{9,55} \\
& \mathrm{P}=\frac{5153,48 \times 14,6}{9,55}=7,9 \mathrm{~kW}
\end{aligned}
$$

\section{Perhitungan Daya listrik}

Dengan memperhitungkan torsi input $\left(T_{1}\right)$ sebesar 53,74 Nm dan kecepatan putaran input $\left(n_{1}\right)$ sebesar $1400 \mathrm{rpm}$, maka daya listrik yang dibutuhkan escalator adalah :

$$
\mathrm{P}=\frac{53,74 \times 1400}{9,55}=7,9 \mathrm{kw}
$$

\section{Pemilihan Motor}

Dari besar daya listrik dan kecepatan input yang telah diketahui maka dengan melihat katalog motor listrik Fujita didapat motor dengan rating yang mendekati setingkat di atas daya listrik yang telah diperhitungkan dengan spesifikasi sebagai berikut:

1. Daya Output $(\mathrm{P})=11 \mathrm{kw}$

2. Tegangan $(\mathrm{V})=380$ volt

3. Kecepatan putaran $(\mathrm{n})=1460 \mathrm{rpm}$

4. $\quad \operatorname{Arus}(\mathrm{I})=22.3 \mathrm{~A}$

5. Power factor $=0,84$

Pemilihan motor dengan kapasitas daya motor yang lebih besar dibandingkan perhitungan agar motor tidak dibebani $100 \%$ untuk menjaga lifetime dari motor. Karena besar daya motor yang digunakan lebih besar dari $5 \mathrm{kw}$ maka motor listrik akan distarting dengan pengasutan star delta untuk mengurangi kenaikan arus saat starting.

\section{N. Perubahan Perhitungan Karena Pemilihan Motor}

Pemilihan motor dengan spesifikasi yang tidak bisa benar-benar sama dengan perhitungan sebelumnya menyebabkan beberapa perubahan nilai perhitungan. Nilai-nilai tersebut dihitung lagi sebagai berikut. 
88 Muhammad Hendrik Septiawan, Dadang Suherman, Prihadi Murdiyat. Perencanaan Eskalator Lantai Satu ke Dua pada Gedung Direktorat Politeknik Negeri Samarinda dengan Kendali PLC

\section{Perhitungan Kecepatan Eskalator Sesuai Kecepatan Motor}

Karena motor yang digunakan memiliki kecepatan putar sebesar $1460 \mathrm{rpm}$, nilai kecepatan putaran input dan output gearbox berubah. Untuk gear ratio (i) $=96,2$, kecepatan putaran sprocket menjadi :

$$
\begin{aligned}
& \mathrm{i} \quad=\frac{n_{1}}{n_{2}} \\
& 96,2=\frac{1460}{n_{2}} \\
& n_{2}=\frac{1460}{96,2} n_{2}=15,2 \mathrm{rpm}
\end{aligned}
$$

Karena kecepatan putaran sprocket berubah maka kecepatan eskalator yang sebelumnya sebesar 0,5 $\mathrm{m} / \mathrm{s}$ menjadi berubah pula. Untuk kecepatan putaran sprocket $(\mathrm{n})=15,2 \mathrm{rpm}$ diperoleh :

$$
\omega=\frac{2 \pi}{60} \times \mathrm{n}=\frac{2 \pi}{60} \times 15,2=1,59 \mathrm{rad} / \mathrm{s}
$$

Selanjutnya karena jari-jari sprocket $(r)=0,3085 \mathrm{~m}$, kecepatan linier escalator menjadi:

$$
\mathrm{v}=\omega \times \mathrm{r}=1,59 \times 0,3085=0,49 \mathrm{~m} / \mathrm{s}
$$

\section{Perhitungan Torsi Input Setelah Pemilihan Motor}

Karena terdapat perbedaan kecepatan input dan output sebelum pemilihan motor dengan setelah pemilihan motor dimana sebelum pemilihan motor kecepatan input sebesar $1400 \mathrm{rpm}$ setelah pemilihan motor kecepatan input menjadi $1460 \mathrm{rpm}$ dan kecepatan output sebelum pemilihan motor sebesar 14,6 rpm setelah pemilihan motor menjadi 15,2 rpm, maka dengan memasukkan torsi output $\left(T_{2}\right)=5153,48 \mathrm{Nm}$, diperoleh :

$$
\begin{aligned}
\frac{n_{1}}{n_{2}} & =\frac{T_{2}}{T_{1}} \\
\frac{1460}{15,2} & =\frac{5153,48}{T_{1}} \\
T_{1} & =\frac{5153,48 \times 15,2}{1460}=53,65 \mathrm{Nm}
\end{aligned}
$$

\section{Perhitungan Daya Mekanik Setelah Pemilihan Motor}

Selain itu juga diilakukan penghitungn daya mekanik menjadi:

$$
\begin{aligned}
& \mathrm{P}=\frac{T \times n}{9,55} \\
& \mathrm{P}=\frac{5153,48 \times 15,2}{9,55}=8,2 \mathrm{~kW}
\end{aligned}
$$

\section{Perhitungan Daya Listrik Setelah Pemilihan Motor}

Sementara itu perhitungan daya listrik setelah pemilihan motor menjadi seperti berikut :

$$
\mathrm{P}=\frac{T \times n}{9,55}=\frac{53,65 \times 1460}{9,55}=8,2 \mathrm{kw}
$$

Karena daya listrik dan mekanik yang dibutuhkan sebesar 8,2 kw sedangkan daya motor yang digunakan sebesar $11 \mathrm{kw}$ maka motor yang dipilih masih dapat digunakan untuk menggerakkan eskalator setelah adanya perbedaan kecepatan eskalator sebelum dan sesudah pemilihan motor, karena daya listrik dan mekanik yang dibutuhkan lebih kecil dibandingkan daya motor yang digunakan. 


\section{O. Penentuan Besar MCB Untuk Motor Listrik}

Untuk menentukan besar MCB perlu diketahui nilai arus nominal motor. Daya motor yang digunakan adalah $11 \mathrm{kw}$ sedangkan daya motor yang dihitung adalah sebesar 8,2 kw. Arus nominal yang digunakan sebagai acuan penentuan pengaman adalah arus nominal yang tertera pada katalog motor yang digunakan yaitu sebesar 22.3 Ampere. Menurut PUIL 2000 pasal 5.5.5.2.2 untuk motor jenis rotor sangkar kapasitas pemutus sirkit yang digunakan $250 \%$ dari arus beban penuh. Maka, besarnya rating MCB yang digunakan adalah:

$$
\text { Besar } \mathrm{MCB}=\text { In } \times 250 \%=22,3 \times 250 \%=55,75 \mathrm{~A} \text { (setelan maksimum) }
$$

Karena besar MCB yang dihitung merupakan nilai pengenal atau setelan tertinggi gawai proteksi sirkit motor maka dipilihlah MCB dengan rating 50 Ampere.

\section{P. Penentuan Besar Kapasitas TOR Untuk Motor Listrik}

Besar dari kapasitas TOR yang digunakan bergantung pada arus nominal motor yang telah dihitung pada penentuan besar kapasitas MCB, di mana arus nominal motor sebesar 22,3 Ampere. Sehingga untuk rating TOR yang diperoleh:

$$
\mathrm{TOR}=\mathrm{In} \times 100 \%=22,3 \times 100 \%=22,3 \mathrm{~A}
$$

Berdasarkan arus nominal tersebut dipilihlah TOR dengan rating 16-24 Ampere.

\section{Q. Penentuan Besar Penghantar Motor Listrik Eskalator}

Untuk besar penghantar dapat ditentukan dengan mengetahui besar kuat hantar arus dari kabel yang akan digunakan, yaitu :

$$
\mathrm{KHA}=\operatorname{In} \times 125 \%=22,3 \times 125 \%=27,88 \mathrm{~A}
$$

Maka sesuai PUIL, besar penampang yang digunakan adalah NYY $4 \times 4 \mathrm{~mm}^{2}$.

\section{R. Penentuan Besar Kontaktor Yang Digunakan}

Menurut PUIL 2000 besar kapasitas kontaktor yang digunakan sekurang - kurangnya 115\% dari arus beban penuh motor. Arus nominal motor sesuai dengan katalog motor adalah sebesar 22,3 Ampere dan daya motor adalah $11 \mathrm{kw}$ Sehingga dapat dihitung besar kapasitas kontaktor :

$$
\text { Kontaktor }=\operatorname{In} \times 115 \%=22,3 \times 115 \%=25,65 \mathrm{~A}
$$

Untuk mendekati nilai tersebut, kapasitas kontaktor di pasaran yang dapat digunakan adalah 32 Ampere.

\section{S. Pemilihan Bearing}

Untuk pemilihan bearing disini kita lihat beban total yang akan ditumpu oleh bearing sebagai acuan. Dengan melihat beban total yang akan ditumpu oleh bearing yaitu sebesar 3405,7 kg maka dipilihlah bearing produk NSK series 6828 ball bearing dengan spesifikasi sebagai berikut:

1. Beban maksimum bearing $=8580 \mathrm{lb}=3891,16 \mathrm{~kg}$

2. Kecepatan maksimum $=1000 \mathrm{rpm}$

3. Diameter dalam $=140 \mathrm{~mm}$

4. Diameter luar $=175 \mathrm{~mm}$ 
90 Muhammad Hendrik Septiawan, Dadang Suherman, Prihadi Murdiyat. Perencanaan Eskalator Lantai Satu ke Dua pada Gedung Direktorat Politeknik Negeri Samarinda dengan Kendali PLC

5. Diameter untuk shaft $=5,768$ inch $=146 \mathrm{~mm}$

6. Diameter untuk rumah bearing $=6,634 \mathrm{inch}=168,5036 \mathrm{~mm}$

\section{T. Pemilihan Poros}

Pada data bearing di atas telah didapatkan data untuk diameter shaft yang akan digunakan yaitu mengikuti rekomendasi perusahaan agar shaft yang digunakan cocok untuk pemasangan bearing nanti dimana diameter shaft yang digunakan yaitu sebesar $146 \mathrm{~mm}$. Bahan shaft yang digunakan adalah baja karbon s30c dengan kekuatan tarik $48 \mathrm{~kg} / \mathrm{mm}^{2}$. Sehingga besarnya beban yang mampu ditopang oleh shaft adalah :

$$
\begin{gathered}
\text { Luas penampang shaft }=\pi \times \frac{D^{2}}{4}=3.14 \times \frac{146^{2}}{4}=16733 \mathrm{~mm}^{2} \\
\tau_{a}=\frac{\sigma_{B}}{\left(S f_{1} \times S f_{2}\right)}=\frac{48}{6 \times 3}=2,67 \mathrm{~kg} / \mathrm{mm}^{2}
\end{gathered}
$$

Daya topang shaft $=2,67 \times 16733=44677,11 \mathrm{~kg}$

Karena daya topang shaft lebih besar daripada seluruh beban yang ada pada eskalator maka shaft tersebut dapat digunakan.

\section{U. Pemilihan Brake Eskalator}

Dalam memilih brake yang tepat untuk eskalator, besar torsi yang hendak direm adalah torsi output yaitu sebesar 5153,48 Nm sehingga dipilihlah brake dengan torsi pengereman minimum sebesar $5153,48 \mathrm{Nm}$ untuk memastikan eskalator akan berhenti secara langsung ketika melakukan pengereman.

\section{Gambar Rangkaian Pengawatan}

Rangkaian pengawatan seperti yang ditunjukkan pada gambar-gambar di bawah ini terdiri dari rangkaian pengawan sistem kontrol dan rangkaian pengawatan daya. Tujuan dibuatnya rangkaian pengawatan ini agar memudahkan pembacaan dalam melakukan perbaikan maupun perawatan sistem.
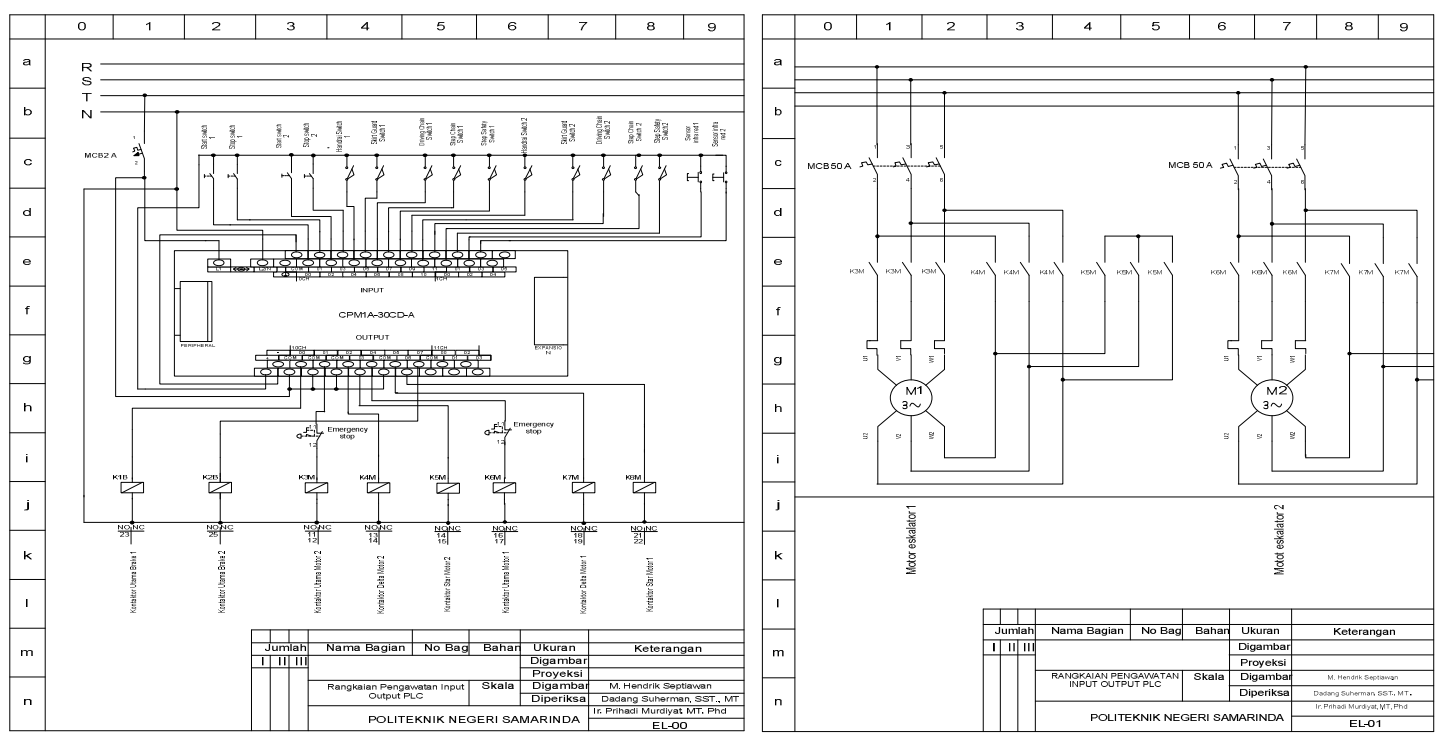

Gambar 6 Rangkaian Pengawatan EL-00 dan EL-01 


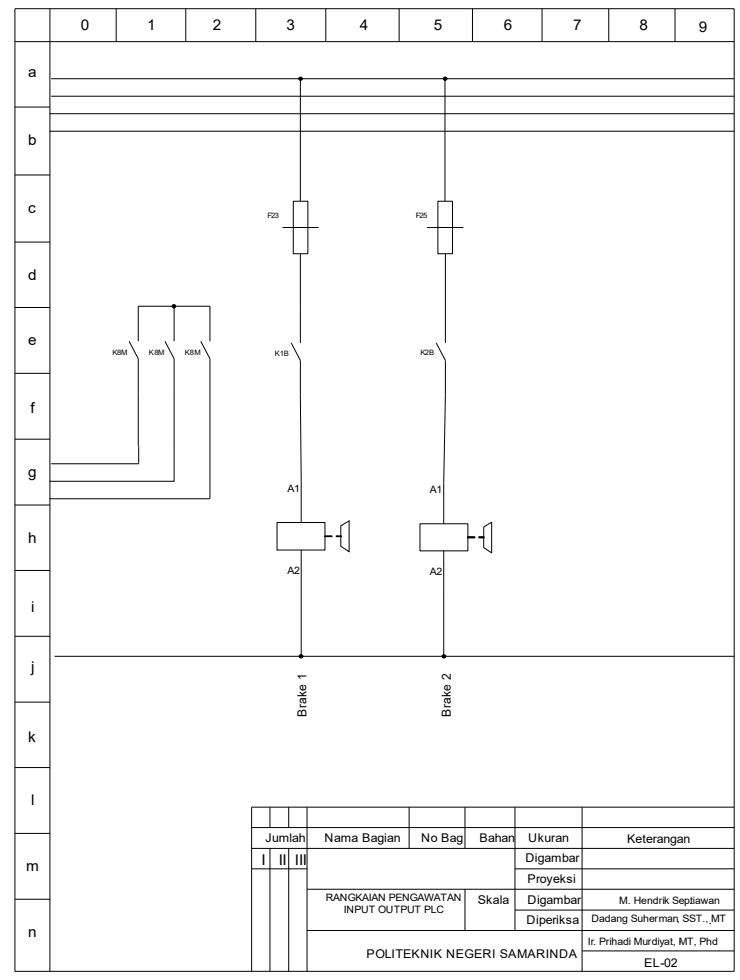

Gambar 7 Rangkaian Pengawatan EL-02

\section{W. Diagram Kontrol}

Sistem kontrol untuk eskalator ini menggunakan PLC dimana akan lebih memudahkan pemantauan terhadap masalah yang terjadi pada sistem kerja eskalator tersebut. Satu buah PLC digunakan untuk mengontrol 2 buah eskalator dirasa cukup karena jumlah input dan output yang kita gunakan cukup banyak dan PLC dapat menambah jumlah input output dengan menggunakan expansion apabila dirasa jumlah input dan output yang ada tidak mencukupi. Pada diagram kontrol seperti yang ditunjukkan pada Gambar di bawah ini. Sistem kontrol eskalator ini menggunakan CXProgrammer sebagai aplikasi dalam membuat kontrol kerja PLC.
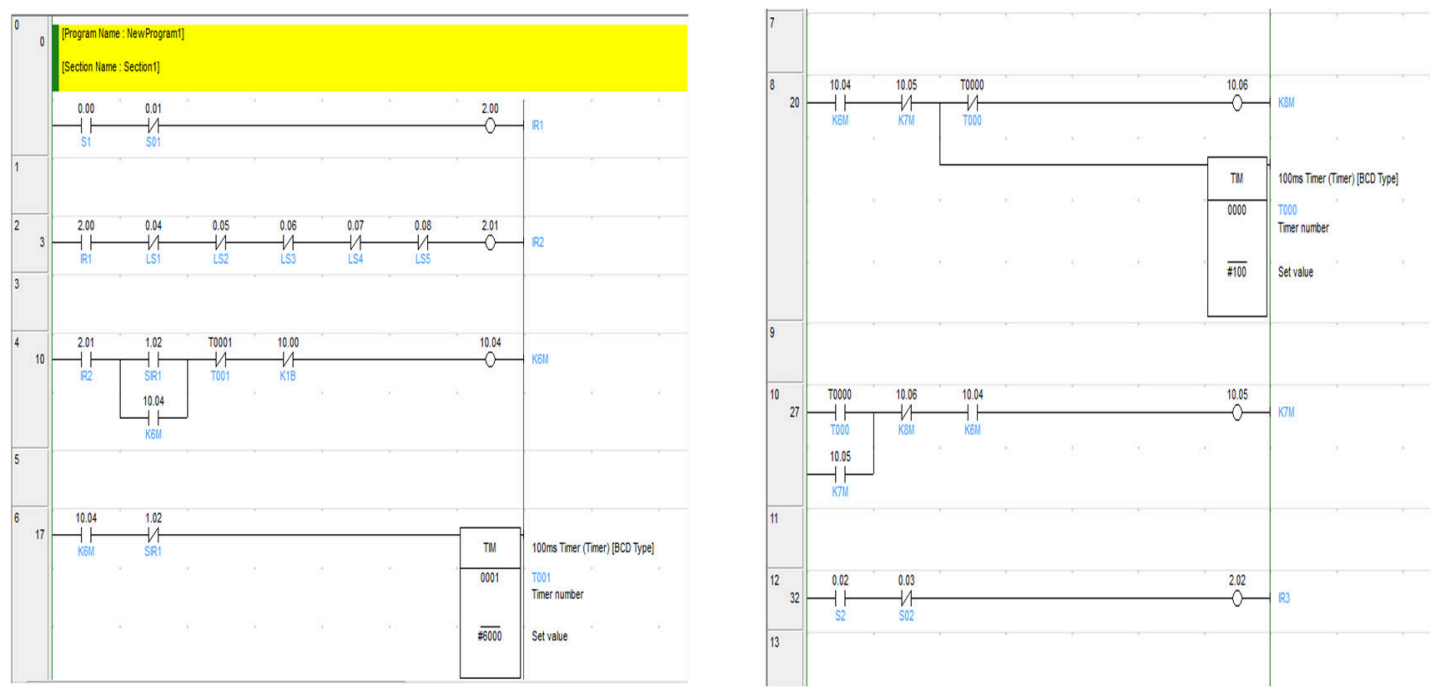

Gambar 8 Diagram Kontrol PLC Rung 0-13 
92 Muhammad Hendrik Septiawan, Dadang Suherman, Prihadi Murdiyat. Perencanaan Eskalator Lantai Satu ke Dua pada Gedung Direktorat Politeknik Negeri Samarinda dengan Kendali PLC
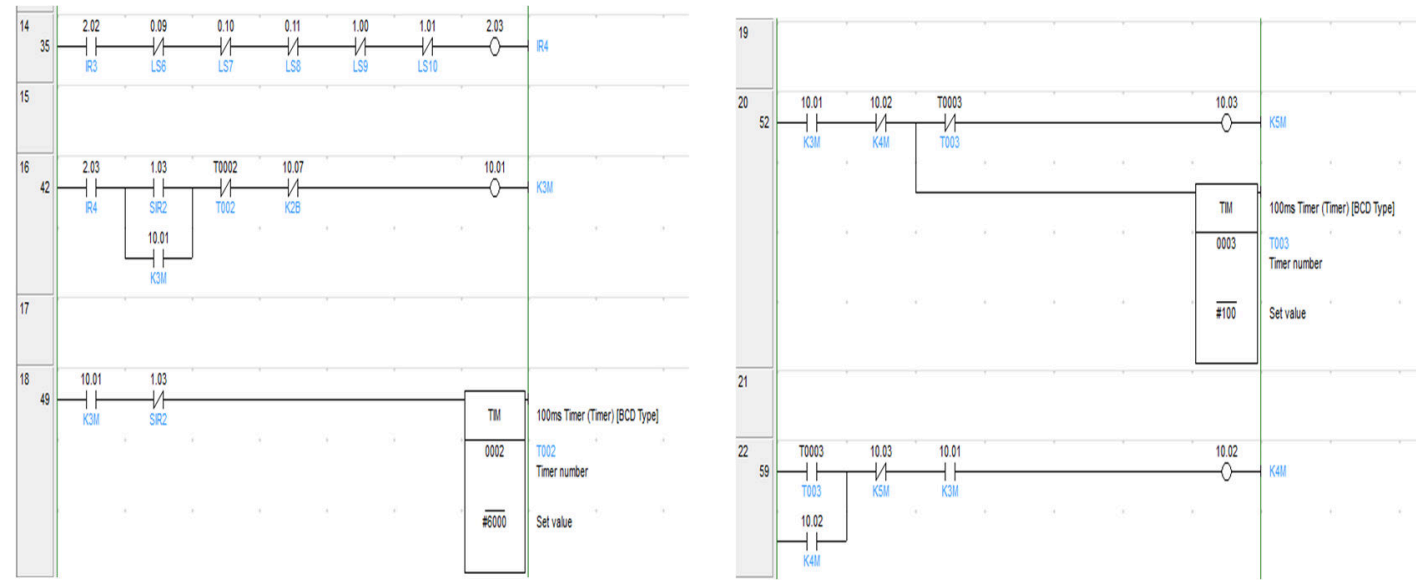

Gambar 9 Diagram Kontrol PLC Rung 14-22
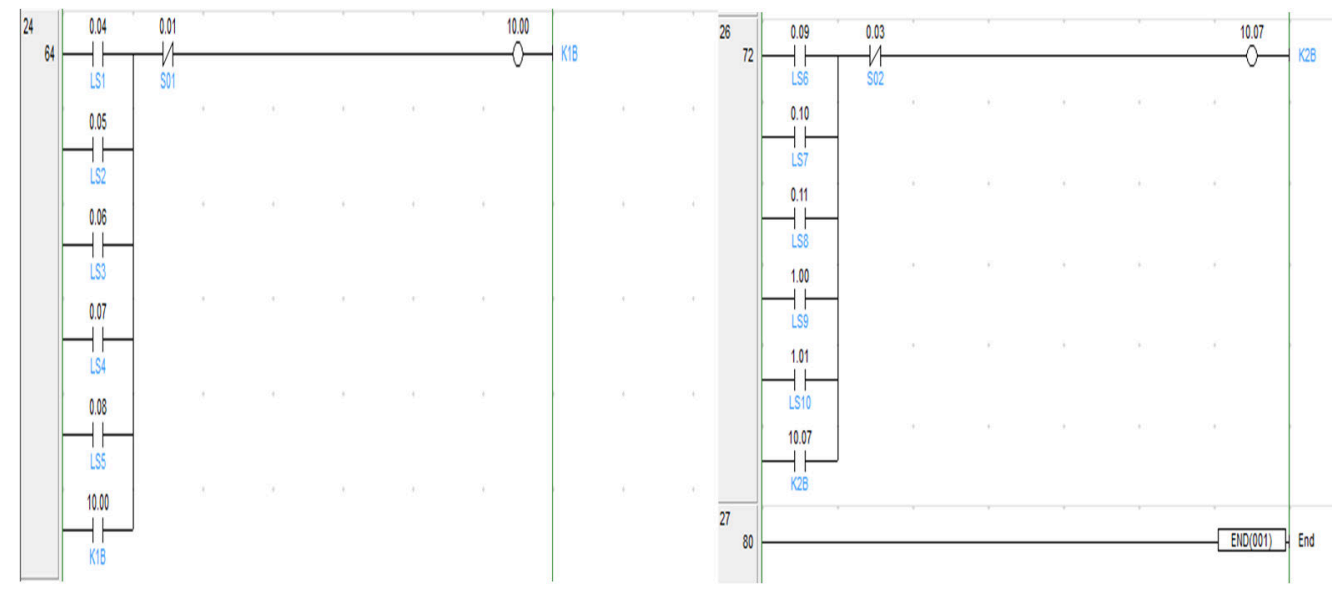

Gambar 10 Diagram Kontrol PLC Rung 23-27

\section{Simbol List}

Kode yang digunakan dalam diagram kontrol PLC yang ditunjukkan dalam Tabel 1. 
Tabel 4.1 Simbol List PLC

\begin{tabular}{|c|c|c|}
\hline Kode & Alamat & Keterangan \\
\hline S1 & 0.00 & Kunci start 1 \\
\hline $\mathrm{S} 01$ & 0.01 & Kuncistop 1 \\
\hline S2 & 0.02 & Kunci start 2 \\
\hline $\mathrm{S} 02$ & 0.03 & Kunci stop 2 \\
\hline LS1 & 0.04 & Handrail entry 5 witch 1 \\
\hline LS2 & 0.05 & Skirt guard safety switch 1 \\
\hline LS3 & 0.06 & Driving chain safety switch 1 \\
\hline LS4 & 0.07 & Step chain safety switch 1 \\
\hline LS5 & 0.08 & Step safety switch 1 \\
\hline LS6 & 0.09 & Handrail entry 5 witch 2 \\
\hline LS7 & 0.10 & Skirt guard safety switch 2 \\
\hline LS8 & 0.11 & Driving chain safety switch 2 \\
\hline LS9 & 1.00 & Step chain safety switch 2 \\
\hline LS10 & 1.01 & Step safety switch 2 \\
\hline SIR1 & 1.02 & Sens or infra red 1 \\
\hline SIR2 & 1.03 & Sens or infra red 2 \\
\hline T000 & T0000 & Timer waktu jeda star delta motor 1 \\
\hline T001 & T0001 & Timer waktu jeda eskalator 1 berhenti \\
\hline $\mathrm{T} 002$ & T0002 & Timer waktu jeda eskalator 2 berhenti \\
\hline T003 & T0003 & Timer waktu jeda star delta motor 2 \\
\hline K1B & 10.00 & Kontaktor utama brake 1 \\
\hline $\mathrm{K} 2 \mathrm{~B}$ & 10.07 & Kontaktor utama brake 2 \\
\hline $\mathrm{K} 3 \mathrm{M}$ & 10.01 & Kontaktor utama motor 2 \\
\hline $\mathrm{K} 4 \mathrm{M}$ & 10.02 & Kontaktor delta motor 2 \\
\hline $\mathrm{K} 5 \mathrm{M}$ & 10.03 & Kontaktor bintang motor 2 \\
\hline $\mathrm{K} 6 \mathrm{M}$ & 10.04 & Kontaktor utama motor 1 \\
\hline $\mathrm{K} 7 \mathrm{M}$ & 10.05 & Kontaktor delta motor 1 \\
\hline K8M & 10.06 & Kontaktor star motor 1 \\
\hline IRl & 2.00 & Internal relay 1 \\
\hline IR2 & 2.01 & Internal relay 2 \\
\hline IR3 & 2.02 & Internal relay 3 \\
\hline IR4 & 2.03 & Internal relay 4 \\
\hline
\end{tabular}

\section{Y. Deskripsi Kerja Rangkaian Kontrol}

1. Ketika kunci start 1 di putar ON akan mengaktifkan internal relay yang akan mengalirkan arus menuju sensor infra merah 1 . Ketika sensor infra merah 1 mendeteksi adanya penumpang maka akan memberikan sinyal kepada input PLC untuk mengaktifkan kontaktor utama eskalator 1 . Ketika kontaktor utama eskalator 1 bekerja maka akan mengaktifkan motor dengan mengaktifkan timer, mengaktifkan kontaktor star, selama kontaktor star bekerja maka motor bekerja dengan rangkaian bintang kemudian mengaktifkan kontaktor delta setelah itu motor akan bekerja pada rangkaian delta. Timer 000 berfungsi untuk memberikan waktu jeda perpindahan rangkaian star ke delta pada motor 1 . Timer tersebut disetting dengan waktu jeda selama $100 \mathrm{~ms}$. Ketika tidak ada penumpang yang dideteksi oleh sensor infra merah maka T001 akan bekerja untuk memberikan waktu jeda pada motor untuk berhenti, namun jika sensor infra merah mendeteksi adanya penumpang sebelum motor listrik berhenti maka timer tersebut akan direset ke waktu semula dan motor listrik tetap bekerja hingga benar-benar tidak ada penumpang selama jeda waktu yang diberikan timer yaitu selama 10 menit. Ketika terjadi sebuah masalah pada eskalator dimana memicu kontak pengaman bekerja maka akan mengaktifkan brake 1 , ketika brake 1 aktif, arus menuju kontaktor utama akan diputus, motor akan berhenti bekerja dan brake akan bekerja untuk menghentikan eskalator yang masih bergerak. Brake akan terus bekerja hingga kita mengaktifkan kunci stop dan brake akan berhenti bekerja dan arus menuju sensor infra merah akan diputus begitu juga arus menuju kontaktor utama 1 .

2. Ketika kunci start 2 di putar ON akan mengaktifkan internal relay yang akan mengalirkan arus menuju sensor infra merah 2. Ketika sensor infra merah 2 mendeteksi adanya penumpang maka akan memberikan sinyal kepada input PLC untuk mengaktifkan kontaktor utama eskalator 2. Ketika kontaktor utama eskalator 2 bekerja maka akan mengaktifkan motor dengan mengaktifkan 
94 Muhammad Hendrik Septiawan, Dadang Suherman, Prihadi Murdiyat. Perencanaan Eskalator Lantai Satu ke Dua pada Gedung Direktorat Politeknik Negeri Samarinda dengan Kendali PLC

timer, mengaktifkan kontaktor star, selama kontaktor star bekerja maka motor bekerja dengan rangkaian bintang kemudian mengaktifkan kontaktor delta setelah itu motor akan bekerja pada rangkaian delta. Timer 003 berfungsi untuk memberikan waktu jeda perpindahan rangkaian star ke delta pada motor 2. Timer tersebut disetting dengan waktu jeda selama 100 ms. Ketika tidak ada penumpang yang dideteksi oleh sensor infra merah maka T002 akan bekerja untuk memberikan waktu jeda pada motor untuk berhenti, namun jika sensor infra merah mendeteksi adanya penumpang sebelum motor listrik berhenti maka timer tersebut akan direset ke waktu semula dan motor listrik tetap bekerja hingga benar-benar tidak ada penumpang selama jeda waktu yang diberikan timer yaitu selama 10 menit. Ketika terjadi sebuah masalah pada eskalator dimana memicu kontak pengaman bekerja maka akan mengaktifkan brake 2 , ketika brake 2 aktif, arus menuju kontaktor utama akan diputus, motor akan berhenti bekerja dan brake akan bekerja untuk menghentikan eskalator yang masih bergerak. Brake akan terus bekerja hingga kita mengaktifkan kunci stop dan brake akan berhenti bekerja dan arus menuju sensor infra merah akan diputus begitu juga arus menuju kontaktor utama 2.

\section{KESIMPULAN}

1. Tahap perencangan diperoleh hasil perhitungan mekanik eskalator berupa pemilihan gearbox, motor, bearing dan poros.

2. Telah dibuat perencanaan sistem kontrol untuk eskalator menggunakan PLC dimana akan lebih memudahkan pemantauan terhadap masalah yang terjadi pada sistem kerja eskalator.

\section{DAFTAR PUSTAKA}

[1] Nutranta and Ariswan. [Online] http://eprints.polsri.ac.id/2760/3/3.\%20BAB\%20II.pdf. 2019.

[2] Firmansyah. "Perencanaan Eskalator Lantai Satu ke Dua Gedung Pusat Perbelanjaan Metropolis Tanggerang ". Jakarta: Universitas Mercubuana. 2007.

[3] MitsubishiElectric. "Elevator" [Online].http://www.mitsubishielectric.com/elevator/overview/e_m_walks/e_s_equipment.html.

[4] Sularso MSME. "Dasar Perencanaan dan Pemilihan Elemen Mesin" Jakarta, Indonesia: Pradnya Paramita. 2004

[5] National Senior Certificate."Mechanical Technology Formula Sheet" Bangladesh: The Institution of Engineers Bangladesh. 2017.

[6] Suyamto. "Analisis Daya dan Torsi pada Motor Induksi". Jurnal Sekolah TInggi Teknologi Nuklir, 2009. vol. 1, no. ISSN : 1978-0176. 